\title{
Britain ready to open a telephone line to Japan
}

\section{- British and Japanese companies competing - Cable and Wireless breakthrough expected}

Tokyo

A dogged effort by Britain's Cable and Wireless to break into Japan's international telecommunications market seems set to succeed. Last week, the Ministry of Post and Telecommunications and Prime Minister Yasuhiro Nakasone indicated willingness to consider separate licence applications from two competing consortia - one headed by the British company, the other made up entirely of Japanese companies. The decision came after efforts to merge the competitors into a single international consortium fell through

It is more than a year since Cable and Wireless and C. Itoh and Co., a leading Japanese trading company, announced plans to establish an international telecommunications company, International Digital Communications (IDC), to compete with the recently privatized monopoly Kokusai Denshin Denva (KDD) (see Nature 321, 803; 1986). At about the same time, another consortium headed by the rival trading companies Mitsui and Co., Mitsubishi Corporation and Sumitomo Corporation formed International Telecom Japan (ITJ), to prepare for entry into the market.

But from the outset there was opposition to the Cable and Wireless group. At first, the Ministry of Post and Telecommunications and KDD insisted there was no room for a third company - an argument belied by KDD's own projections which forecast a tripling in the

\section{Soviet satellite down}

\section{Washington}

A Soviex satellite came down unexpectedly in the middle of the Pacific Ocean at 0727 GMT on 10 August, nine days after it was launched into a polar orbit. According to the US Space Command in Colorado Springs, Cosmos 1971 splashed down about $4,800 \mathrm{~km}$ north of New Zealand.

The satellite carried scientific equipment for Earth observations and a radio system for accurate determination of its orbit, according to the Soviet news agency TASS. The US Space Command estimates that the satellite weighed approximately 15 tonnes. Tracking data indicated Cosmos 1971 skipped off the atmosphere once before re-entry. Its terminal velocity was estimated at $27,000 \mathrm{~km} / \mathrm{hr}$.

TASS said that the satellite carried no dangerous cargo, and there are no reports of debris striking populated areas. value of the market by 1995 . Then the Federation of Economic Organizations, with the ministry's blessing, proposed a merger of ITJ and IDC that would have slashed Cable and Wireless's equity holding from 20 per cent to 3 per cent. The ministry argued that it was against "national security" interests for a foreign company to have a controlling interest in a telecommunications company. But protests and threats of retaliation by the US and British governments led to a retraction of the proposed equity holdings.

The ministry, however, continued to insist on a merger of ITJ and IDC, although the two companies have totally incompatible plans: IDC intends to lay its own trans-Pacific optical fibre cable, while ITJ wants to lease circuits on cables to be laid by KDD and American Telephone and Telegraph.

Merger talks have been held on several occasions over the past six months but with no success. The two groups remain resolutely divided over the cable issue. In a last-ditch effort to reach a compromise, IDC at the end of last month proposed establishment of a separate company to lay and operate the trans-Pacific cable; the various shareholders in the merged company would be free to invest (or not invest) in the proposed cable company as they wished. But last week ITJ formally rejected this proposal.

Prime Minister Yasuhiro Nakasone told British Prime Minister Margaret Thatcher during the Venice summit in June that the two consortia would be allowed to apply for separate licences if merger talks failed, a stance that was confirmed by the Ministry of Post and Telecommunications in talks with the US Federal Communications Commission at the end of June. IDC and ITJ are expected to make separate applications soon.

Cable and Wireless estimate that only about one million of Japan's 45 million telephones have access to direct dialling overseas (access requires application to KDD and takes about a month). One factor slowing expansion of the Japanese market is cost. A telephone call to Britain from Japan costs twice that of one made in the opposite direction. Cable and Wireless' director of special projects, Jonathan Solomon, is confident that IDC will be able to undercut present KDD rate by a third, a move that should stimulate additional market growth.

David Swinbanks
US - Japanese supercomputer accord reached

\section{Tokyo}

JAPAN and the United States have reached an agreement to simplify procedures for government procurement of supercomputers in Japan.

The accord, formalized on Friday through the exchange of letters between US trade representative Clayton Yeutter and Nabuo Matsunaga, Japanese ambassador to the United States, is intended to help US manufacturers sell multi-million dollar supercomputers to Japanese public institutes. But it is unlikely that the revised procedures will lead to a substantial increase in sales.

Friday's agreement, which took nine months to negotiate, follows the Japanese government's issue last month of new guidelines that came into effect on $1 \mathrm{Aug}$ ust. Under the new rules, public institutions (universities and research institutes) must announce well in advance plans to purchase or lease supercomputers. The new procedures require desired specifications be provided to all potential bidders.

The agreement does not end differences between the United States and Japan over supercomputer sales practices. At the signing ceremony, Yeutter said discount practices of Japanese supercomputer manufacturers remain a "major problem". Several universities in Japan have obtained supercomputers from domestic manufacturers at huge discount.

Of the 79 supercomputers delivered or ordered in Japan, only 11 (all Cray computers) are US-made, even though Cray computers have much better software than Japanese brands and dominate the market in the rest of the world.

But cracks are beginning to appear in the public sector market. In July, Aichi Institute of Technology announced its intention to purchase a $\$ 3.74$ million Cray computer. And, as part of a $\$ 40,000$ million supplementary budget to boost domestic demand, the Japanese government plans an "emergency import" of two or three US supercomputers (one of which is expected to go to the Advanced Telecommunications Research Institute International in the new academic city under development in the Kansai region of western Japan). But with many Japanese universities already having close links with particular domestic manufacturers a rush to buy US supercomputers cannot be expected. Broad interconnected computer systems, not just supercomputers, are becoming the norm. And once a particular system and software have been installed, it does not pay to change. David Swinbanks 